\title{
Weak Form Efficiency In Indian Stock Markets
}

Rakesh Gupta, (E-mail: r.gupta@cqu.edu.au), Central Queensland University, Australia Parikshit K. Basu, (E-mail: pbasu@csu.edu.au), Charles Sturt University, Australia

\begin{abstract}
Hypothesis of Market Efficiency is an important concept for the investors who wish to hold internationally diversified portfolios. With increased movement of investments across international boundaries owing to the integration of world economies, the understanding of efficiency of the emerging markets is also gaining greater importance. In this paper we test the weak form efficiency in the framework of random walk hypothesis for the two major equity markets in India for the period 1991 to 2006. The evidence suggests that the series do not follow random walk model and there is an evidence of autocorrelation in both markets rejecting the weak form efficiency hypothesis.
\end{abstract}

\section{INTRODUCTION}

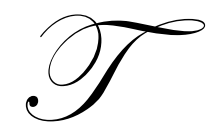

he term market efficiency in capital market theory is used to explain the degree to which stock prices reflect all available, relevant information. The concept of Efficiency Market Hypothesis (EMH) is based on the arguments put forward by Samuelson (1965) that anticipated price of an asset fluctuate randomly. Fama (1970) presented a formal review of theory and evidence for market efficiency and subsequently revised it further on the basis of development in research (Fama 1991).

Efficiency of equity markets has important implications for the the investment policy of the investors. If the equity market in question is efficient researching to find miss-priced assets will be a waste of time. In an efficient market, prices of the assets will reflect markets' best estimate for the risk and expected return of the asset, taking into account what is known about the asset at the time. Therefore, there will be no undervalued assets offering higher than expected return or overvalued assets offering lower than the expected return. All assets will be appropriately priced in the market offering optimal reward to risk. Hence, in an efficient market an optimal investment strategy will be to concentrate on risk and return characteristics of the asset and/or portfolio. However, if the markets were not efficient, an investor will be better off trying to spot winners and losers in the market and correct identification of miss-priced assets will enhance the overall performance of the portfolio Rutterford (1993). EMH has a twofold function - as a theoretical and predictive model of the operations of the financial markets and as a tool in an impression management campaign to persuade more people to invest their savings in the stock market (Will 2006).

The understanding of efficiency of the emerging markets is becoming more important as a consequence of integration with more developed markets and free movement of investments across national boundaries. Traditionally more developed Western equity markets are considered to be more efficient. Contribution of equity markets in the process of development in developing countries is less and that resulted in weak markets with restrictions and controls (Gupta, 2006)

In the last three decades, a large number of countries had initiated reform process to open up their economies. These are broadly considered as emerging economies. Emerging markets have received huge inflows of capital in the recent past and became viable alternative for investors seeking international diversification. Among the emerging markets India has received it's more than fair share of foreign investment inflows since its reform process began. One reason could be the Asian crisis which affected the fast developing Asian economies of the time (also some times collectively called 'tiger economies'). India was not affected by the Asian crisis and has maintained its high economic growth during the period (Gupta and Basu 2005). 
Today India is one of the fastest growing emerging economies in the world. The reform process in India officially started in 1991. As a result, demand for investment funds is growing significantly and capital market growth is expected to play an increasingly important role in the process. The capital market reforms in India present a case where a judicious combination of competition, deregulation and regulation has led to sustained reforms and increased efficiency (Datar and Basu 2004).

At this transitional stage, it is necessary to assess the level of efficiency of the Indian equity market in order to establish its longer term role in the process of economic development. However, studies on market efficiency of Indian markets are very few. They are also dated and mostly inconclusive. The objective of this study is to test whether the Indian equity markets are weak form efficient or not. EMH, similar to other theories that require future expected prices or returns, use past actual prices or returns for the tests. Sets of share price changes are tested for serial independence. Random walk theory for equity prices show an equities market in which new information is quickly discounted into prices and abnormal or excess returns can not be made from observing past prices (Poshakwale 1996).

The next section of this paper provides a brief background of the Indian equity market and a brief literature review of studies testing market efficiency in emerging markets. Section 3 explains the methodology used in this study and data sources, followed by the results of the analysis in section 4 . The last section summarizes the conclusions and their implications.

\section{BACKGROUND}

\section{Equity Market In India}

The reform process in India began in early 1990s with stock exchanges and then spread to banks, mutual funds, NBFCs and of late, to insurance companies. However, reforms in equity market in particular commenced in mid-1980s (Datar \& Basu 2004). Mumbai (formerly known as Bombay) Stock Exchange (BSE) has always played the dominant role in the equity market in India. Traditionally, stock exchanges were governed by brokers leading to conflict of interest situation between the interest of common investors and those of brokers/owners of stock exchanges. With the establishment of National Stock Exchange (NSE), a new institutional structure was introduced in India that could ensure smooth functioning of market through a combination of new technology and efficient market design. The Securities Exchange Board of India (SEBI) was set up as a market regulator with statutory powers to control and supervise operations of all participants in the capital market viz. stock exchanges, stock brokers, mutual funds and rating agencies. The development of debt market is another significant development, which has been facilitated by deregulation of administered interest rates. Opening of stock exchange trading to Foreign Institutional Investors (FIIs) and permission of raising funds from international market through equity linked instruments have introduced a degree of competition to domestic exchanges and other market participants. Operations of FIIs have facilitated introduction of best practices and research inputs in trading and risk management systems.

Mumbai stock exchange (BSE), the premier stock exchange of India is probably the oldest stock exchanges in Asia, established in 1875. It was initially named as "Native Share and Share Broker Association" (Poshakwale 1996). Stability in prices for the BSE was considered to be an important feature. During the period 1987 to 1994, average annual price fluctuations of ordinary shares on BSE were $25.1 \%$ as compared with London Stock Exchange (22\%), and the New York Stock Exchange (23.9\%) (Poshakwale 1996).

In this study, to determine market efficiency of equity markets in India, we considered two stock exchanges BSE and NSE. Market capitalization of BSE in July, 2006 was INR 19,871 billion and that of NSE at the same time was INR 18,487 billion. BSE is the oldest stock exchange in India and has the longest data series available. NSE is one of the newer stock exchanges in India. The purpose of establishing NSE was to provide transparency and a better functioning market for the investors. Because of government's support, NSE is fast becoming more accessible market to domestic and foreign investors. The perceived liquidity and accessibility of the NSE market is an important factor and may have different impact on the market efficiency. High liquidity in the market is an important pre-condition for the market efficiency, since a thinly traded market is not in a position to adjust to the new information quickly and 
accurately. Thus, analysis of two major equity markets in India together should provide a more comprehensive and complete picture.

\section{Studies On Market Efficiency}

The efficient market hypothesis is related to the random walk theory. The idea that asset prices may follow a random walk pattern was introduced by Bachelier in 1900 (Poshakwale 1996). The random walk hypothesis is used to explain the successive price changes which are independent of each other.

Fama (1991) classifies market efficiency into three forms - weak, semi-strong and strong. In its weak form efficiency, equity returns are not serially correlated and have a constant mean. If market is weak form efficient, current prices fully reflect all information contained in the historical prices of the asset and a trading rule based on the past prices can not be developed to identify miss-priced assets. Market is semi-strong efficient if stock prices reflect any new publicly available information instantaneously. There are no undervalued or overvalued securities and thus, trading rules are incapable of producing superior returns. When new information is released, it is fully incorporated into the price rather speedily. The strong form efficiency suggests that security prices reflect all available information, even private information. Insiders profit from trading on information not already incorporated into prices. Hence the strong form does not hold in a world with an uneven playing field.

Studies testing market efficiency in emerging markets are few. Poshakwale (1996) showed that Indian stock market was weak form inefficient; he used daily BSE index data for the period 1987 to 1994. Barua (1987), Chan, Gup and Pan (1997) observed that the major Asian markets were weak form inefficient. Similar results were found by Dickinson and Muragu (1994) for Nairobi stock market; Cheung et al (1993) for Korea and Taiwan; and Ho and Cheung (1994) for Asian markets. On the other hand, Barnes (1986) showed a high degree of efficiency in Kuala Lumpur market. Groenewold and Kang (1993) found Australian market semi-strong form efficient.

Some of the recent studies, testing the random walk hypothesis (in effect testing for weak form efficiency in the markets) are; Korea (Ryoo and Smith, 2002; this study uses a variance ratio test and find the market to follow a random walk process if the price limits are relaxed during the period March 1988 to Dec 1988), China, (lee et al 2001; find that volatility is highly persistent and is predictable, authors use GARCH and EGARCH models in this study), Hong Kong (Cheung and Coutts 2001; authors use a variance ratio test in this study and find that Hang Seng index on the Hong Kong stock exchange follow a random walk), Slovenia (Dezlan, 2000), Spain (Regulez and Zarraga, 2002), Czech Republic (Hajek, 2002), Turkey (Buguk and Brorsen, 2003), Africa (Smith et al. 2002; Appiah-kusi and Menyah, 2003) and the Middle East (Abraham et al. 2002; this study uses variance ratio test and the runs test to test for random walk for the period 1992 to 1998 and find that these markets are not efficient).

\section{METHODOLOGY \& DATA}

To test historical market efficiency one can look at the pattern of short-term movements of the combined market returns and try to identify the principal process generating those returns. If the market is efficient, the model would fail to identify any pattern and it can be inferred that the returns have no pattern and follow a random walk process. In essence the assumption of random walk means that either the returns follow a random walk process or that the model used to identify the process is unable to identify the true return generating process. If a model is able to identify a pattern, then historical market data can be used to forecast future market prices, and the market is considered not efficient.

There are a number of techniques available to determine patterns in time series data. Regression, exponential smoothing and decomposition approaches presume that the values of the time series being predicted are statistically independent from one period to the next. Some of these techniques are reviewed in the following section and appropriate techniques identified for use in this study.

Runs test (Bradley 1968) and LOMAC variance ratio test (Lo and MacKinlay 1988) are used to test the weak form efficiency and random walk hypothesis. Runs test determines if successive price changes are independent. It is 
non-parametric and does not require the returns to be normally distributed. The test observes the sequence of successive price changes with the same sign. The null hypothesis of randomness is determined by the same sign in price changes. The runs test only looks at the number of positive or negative changes and ignores the amount of change from mean. This is one of the major weaknesses of the test. LOMAC variance ratio test is commonly criticised on many issues and mainly on the selection of maximum order of serial correlation (Faust, 1992). Durbin-Watson test (Durbin and Watson 1951), the augmented Dickey-Fuller test (Dickey and Fuller 1979) and different variants of these are the most commonly used tests for the random walk hypothesis in recent years (Worthington and Higgs 2003; Kleiman, Payne and Sahu 2002; Chan, Gup and Pan 1997).

Under the random walk hypothesis, a market is (weak form) efficient if most recent price has all available information and thus, the best forecaster of future price is the most recent price. In the most stringent version of the efficient market hypothesis, $\varepsilon_{\mathrm{t}}$ is random and stationary and also exhibits no autocorrelation, as disturbance term cannot possess any systematic forecast errors. In this study we have used returns and not prices for test of market efficiency as expected returns are more commonly used in asset pricing literature (Fama (1998).

Returns in a market conforming to random walk are serially uncorrelated, corresponding to a random walk hypothesis with dependant but uncorrelated increments. Parametric serial correlations tests of independence and nonparametric runs tests can be used to test for serial dependence. Serial correlation coefficient test is a widely used procedure that tests the relationship between returns in the current period with those in the previous period. If no significant autocorrelation are found then the series are expected to follow a random walk.

A simple formal statistical test was introduced was Durbin and Watson (1951). Durbin-Watson (DW) is a test for first order autocorrelation. It only tests for the relationship between an error and its immediately preceding value. One way to motivate this test is to regress the error of time $t$ with its previous value.

$\mathrm{u}_{\mathrm{t}}=\rho \mathrm{u}_{\mathrm{t}-1}+\mathrm{v}_{\mathrm{t}}$

where $v_{t} \sim N\left(0, \sigma_{v}^{2}\right)$.

DW test can not detect some forms of residual autocorrelations, e.g. if $\operatorname{corr}\left(\mathrm{u}_{\mathrm{t}}, \mathrm{u}_{\mathrm{t}-1}\right)=0$ but $\operatorname{corr}\left(\mathrm{u}_{\mathrm{t}}, \mathrm{u}_{\mathrm{t}-2}\right) \neq 0$, DW as defined earlier will not find any autocorrelation. One possible way is to do it for all possible combinations but this is tedious and practically impossible to handle. The second-best alternative is to test for autocorrelation that would allow examination of the relationship between $\mathrm{u}_{\mathrm{t}}$ and several of its lagged values at the same time. The BreuschGodfrey test is a more general test for autocorrelation for the lags of up to r'th order.

$$
\begin{array}{r}
u_{t}=\rho_{1} u_{t-1}+\rho_{2} u_{t-2}+\rho_{3} u_{t-3}+\ldots .+\rho_{r} u_{t-r}+v_{t}, \\
\mathrm{v}_{\mathrm{t}} \sim N\left(0, \sigma_{v}^{2}\right.
\end{array}
$$

Because of the abovementioned weaknesses of the DW test we do not use the DW test in our study. An alternative model which is more commonly used is Augmented Dickey Fuller test (ADF test). Three regression models (standard model, with drift and with drift and trend) are used in this study to test for unit root in the research, (Chan, Gup and Pan 1997; Brooks 2002). In this study we followed the test methodologies from Brooks (2002) with slight adjustments.

$$
\begin{aligned}
& S_{t}=\alpha S_{t-1}+\varepsilon_{t} \\
& S_{t}=u^{*}+\alpha^{*} S_{t-1}+\varepsilon^{*}{ }_{t} \\
& S_{t}=u^{* *}+\beta(t-T)+\alpha^{* *} S_{t-1}+\varepsilon^{* *}{ }_{t} \\
& \text { Where: } \mathrm{St}=\text { the stock price } \\
& \mathrm{u}^{*} \text { and } \mathrm{u}^{* *}=\text { the drift terms } \\
& \mathrm{T}=\text { total number of observations } \\
& \varepsilon_{\mathrm{t}}, \varepsilon_{\mathrm{t}}{ }^{*}, \varepsilon_{\mathrm{t}}^{* *}=\text { error terms that could be ARMA processes with time dependent variances. }
\end{aligned}
$$


Where $S_{t}$ is the logarithm of the price index seen at time $t, u$ is an arbitrary drift parameter, $\alpha$ is the change in the index and $\varepsilon_{t}$ is a random disturbance term. Equation (3) is for the standard model; (4) for the standard model with a drift and (5) for the standard model with drift and trend.

Augmented Dickey-Fuller (ADF) unit root test of nonstationarity is conducted in the form of the following regression equation. The objective of the test is to test the null hypothesis that $\theta=1 \mathrm{in}$ :

$y_{t}=\theta y_{t-1}+u_{t}$

against the one-sided alternative $\theta<1$. Thus the hypotheses to be tested are:

$\mathbf{H}_{\mathbf{0}}: \quad$ Series contains a unit root against

$\mathbf{H}_{1}$ : $\quad$ Series is stationary

In this study we calculate daily returns using daily index values for the Mumbai Stock Exchange (BSE) and National Stock Exchange (NSE) of India. The data is collected from the Datastream data terminal from Macquarie University. The time period for BSE is from $24^{\text {th }}$ May 1991 to $26^{\text {th }}$ May 2006 and for NSE $27^{\text {th }}$ May to $26^{\text {th }}$ May 2006. Stock exchanges are closed for trading on weekends and this may appear to be in contradiction with the basic time series requirement that observations be taken at a regularly spaced intervals. The requirement however, is that the frequency be spaced in terms of the processes underlying the series. The underlying process of the series in this case is trading of stocks and generation of stock exchange index based on the stock trading, as such for this study the index values at the end of each business day is appropriate (French 1980).

Table 1 presents the characteristics of two data sets used in this study. During the period covered in this study, the mean return of the NSE index is much lower than that of the BSE, similarly the variance of NSE is lower as compared with BSE index suggesting a lower risk and a lower average return at NSE as compared with BSE. It is relevant to note that NSE was established by the government of India to improve the market efficiency in Indian stock markets and to break the monopolistic position of the BSE. NSE index is a more diversified one as compared to the same of BSE. This can also be due to the unique nature of India's equity markets, the settlement system on BSE was intermittent (Badla system up until $2^{\text {nd }}$ July 2001) and on NSE it was always cash.

Table 1:

Data characteristics - BSE and NSE - 1991-2006

\begin{tabular}{|c|c|c|c|c|c|c|c|}
\hline Index & Mean & Variance & Minimum & Maximum & Observations & Skewness & Kurtosis \\
\hline BSE & 0.068138 & 2.652610 & -11.251518562 & 18.105585826 & 3915 & 0.328482 & 9.051393 \\
\hline NSE & 0.000591 & 0.000256 & -0.1334028662 & 0.1329113192 & 3915 & -0.209051 & 8.192904 \\
\hline
\end{tabular}

\section{RESULTS}

This study conducts a test of random walk for the BSE and NSE markets in India, using stock market indexes for the Indian markets. It employs unit root tests (augmented Dickey-Fuller (ADF)). We perform ADF test with intercept and no trend and with an intercept and trend. We further test the series using the Phillips-Perron tests and the KPSS tests for a confirmatory data analysis.

In case of BSE and NSE markets, the null hypothesis of unit root is convincingly rejected, as the test statistic is more negative than the critical value, suggesting that these markets do not show characteristics of random walk and as such are not efficient in the weak form. We also test using Phillip-Perron test and KPSS test for confirmatory data analysis and find the series to be stationary. Results are presented in Table 2. For both BSE and NSE markets, the results are statistically significant and the results of all the three tests are consistent suggesting these markets are not weak form efficient. 
Table 2:

\begin{tabular}{|c|c|c|c|c|}
\hline \multicolumn{5}{|c|}{ Results of ADF, PP } \\
\hline Index & $\begin{array}{c}\text { ADF Test Statistic } \\
\text { (5 lags with intercept and } \\
\text { no trend) }\end{array}$ & $\begin{array}{c}\text { ADF Test Statistic } \\
\text { (5 lags with intercept and } \\
\text { trend) }\end{array}$ & $\begin{array}{l}\text { PP unit root test, with } \\
\text { intercept and } 4 \text { lags in } \\
\text { error process }\end{array}$ & $\begin{array}{c}\text { KPSS (Tau statistic) for } \\
\text { lag parameter } 4,3 \text { and } 2 \\
\text { respectively }\end{array}$ \\
\hline BSE & -24.80770 & -24.80455 & -56.22748 & $.13264, .13762, .14178$ \\
\hline NSE & -24.16392 & -24.16776 & -54.82289 & $.11710, .12203, .12576$ \\
\hline te: & $\begin{array}{l}\text { ADF critical values with an } \\
\text { intercept and trend are: }-3.96 \\
\text { PP critical values are: }-3.435 \\
\text { KPSS critical values are: } 0.2 \\
\text { if the tests statistic is less tha } \\
\text { The null hypothesis in the ca } \\
\text { series is stationary. }\end{array}$ & $\begin{array}{l}\text { tercept and no trend are: - } \\
-3.414 \text { and }-3.129 \text { at } 1 \%, 5 \\
2.863 \text { and }-2.567 \text { at } 1 \%, 5 \% \\
0.176,0.146 \text { and } 0.119 \text { at } \\
\text { the critical value. } \\
\text { of ADF and PP is that the }\end{array}$ & $\begin{array}{l},-2.863 \text { and }-2.567 \text { at } 1 \\
\text { d } 10 \% \text { levels. } \\
10 \% \text { respectively. } \\
2.5 \%, 5 \% \text { and } 10 \% \text { level } \\
\text { es is non-stationary, wher }\end{array}$ & $\begin{array}{l}\text { of stationarity is accepted } \\
\text { the case of KPSS test it is }\end{array}$ \\
\hline
\end{tabular}

Results of the study suggest that the markets are not weak form efficient. DW test, which is a test for serial correlations, has been used in the past but the explanatory power of the DW can be questioned on the basis that the DW only looks at the serial correlations on one lags as such may not be appropriate test for the daily data. Current literature in the area of market efficiency uses unit root and test of stationarity. This notion of market efficiency has an important bearing for the fund managers and investment bankers and more specifically the investors who are seeking to diversify their portfolios internationally. One of the criticisms of the supporters of the international diversification into emerging markets is that the emerging markets are not efficient and as such the investor may not be able to achieve the full potential benefits of the international diversification.

\section{CONCLUSIONS \& IMPLICATIONS}

This paper examines the weak form efficiency in two of the Indian stock exchanges which represent the majority of the equity market in India. We employ three different tests ADF, PP and the KPSS tests and find similar results. The results of these tests find that these markets are not weak form efficient. These results support the common notion that the equity markets in the emerging economies are not efficient and to some degree can also explain the less optimal allocation of portfolios into these markets. Since the results of the two tests are contradictory, it is difficult to draw conclusions for practical implications or for policy from the study.

It is important to note that the BSE moved to a system of rolling settlement with effect from $2^{\text {nd }}$ July 2006 from the previously used 'Badla' system. The 'Badla' system was a complex system of forward settlement which was not transparent and was not accessible to many market participants. The results of the NSE are similar (NSE had a cash settlement system from the beginning) to BSE suggesting that the changes in settlement system may not significantly impact the results. On the contrary a conflicting viewpoint is that the results of these markets may have been influenced by volatility spillovers, as such the results may be significantly different if the changes in the settlement system are incorporated in the analysis. The research in the area of volatility spillover has argued that the volatility is transferred across markets (Brailsford, 1996), as such the results of these markets may be interpreted cautiously. For future research, using a computationally more efficient model like generalized autoregressive conditional heteroskesdasticity (GARCH) could help to clear this.

\section{REFERENCES}

1. Abraham, A., Seyyed, F. J., and Alsakran, S. A. (2002) Testing the random behaviour and efficiency of the Gulf stock markets, The Financial Review, 37(3), 469-480.

2. Appiah-Kusi, J. and Menyah, K. (2003) Return predictability in African stock markets, Review of Financial Economics, 12(3). 247-271.

3. Bradley, J. V. (1968). Distribution-Free Statistical Tests, Herman H. J. Lynge and Søn A/S, New Jersey.

4. $\quad$ Barnes P. (1986). Thin Trading and Stock Market Efficiency: The Case Study of the Kuala Lumpur Stock Exchange, Journal of Business Finance \& Accounting, Vol. 13(4), Winter, 609-617. 
5. Barua, S. K. (1987). Some Observations on the Report of the High Powered Committee on the Stock Exchange Reforms, Annual Issue of ICFAI, Dec.

6. Basu, P. and Gupta, R. (2005). Is India vulnerable to financial crisis?: Lessons from the Asian experience. Paper presented at The $18^{\text {th }}$ Australian Finance and Banking Conference 2005, Sydney, December, 14-16, 2005.

7. Brailsford, T. J. (1996). Volatility Spillovers Across the Tasman, Australian Journal of Management, Vol 21, No 1, June.

8. Brooks, C. (2002). Introductory Econometrics for Finance, Cambridge University Press, Cambridge.

9. Chan, K. C., Gup, B. E., and Pan, M. S. (1997). International Stock Market Efficiency and Integration: A Study of Eighteen Nations, Journal of Business Finance and Accounting, 24 (6).

10. Cheung, K.C. and Coutts, J.A. (2001) A note on weak form market efficiency in security prices: Evidence from the Hong Kong stock exchange, Applied Economics Letters, 8(6), 407-410.

11. Cheung, Y. L., Wong, K. A., and Ho, Y. K. (1993) The Pricing of Risky Assets in two Emerging Asian Markets - Korea and Taiwan, Applied Financial Economics 3, Issue 4 Dec. 315-324.

12. Datar, M. K. and Basu, P. K. (2004) Financial sector reforms in India: Some institutional imbalances, Conference Volume, Academy of World Business, Marketing and Management Development Conference, Gold Coast, Australia, July.

13. Dezelan, S. (2000) Efficiency of the Slovenian equity market, Economic and Business Review, 2(1), 61-83.

14. Dickinson, J. P. Muragu K. (1994). Market Efficiency in Developing Countries: A Case Study of the Nairobi Stock Exchange, Journal of Business Finance \& Accounting Vol. 21, No. 1, 133-150.

15. Dickey, D. A. and Fuller, W. A. (1979). Distribution of the estimates for autoregressive time series with a unit root. Journal of American Statistical Association, 74, 427-431.

16. Durbin, J. and Watson, G. S. (1951), Testing for Serial Correlation in Least Squares Regression II. Biometrika 38, 159-178.

17. Fama, E. (1970). Efficient Capital Markets: A Review of Theory and Empirical Work, Journal of Finance, 25, 283-306.

18. Fama, E. (1991). Efficient Capital Markets II, Journal of Finance, 46, 1575-1671.

19. Fama, E. (1998). Market Efficiency, Long-Term Returns, and Behavioural Finance, Journal of Financial Economics, 49:3, 283-306.

20. Faust, J. (1992). When Are Variance Ratio Tests For Serial Dependence Optimal?, Econometrica, Vol. 60, No. 5, 1215-1226.

21. French, K. (1980). Stock Returns and the Weekend Effect, Journal of Financial Economics, 8, 55-69

22. Gupta, R. (2006), Emerging Markets Diversification: Are Correlations Changing Over time? International Academy of Business and Public Administration Disciplines (IABPAD) Conference, January 3-6, 2006, Orlando.

23. Groenewold, N. and Kang, K.C. (1993). The Semi-strong Efficiency of the Australian Share Market, Economic Record, Vol. 69, Iss. 207, December, 405-410.

24. Ho, R. Y. and Cheung, Y. L. (1994). Seasonal pattern in volatility in Asia stock markets, Applied Financial Economics, 4, 61-67.

25. Kleiman, R. T. Payne, J. E., and Sahu, A. P. (2002). Random Walks and Market Efficiency: Evidence from International Real Estate Markets, Journal of Planning Education and Research, Vol. 24, no. 3, 279-297

26. Lee, C.F., Chen, G.M., and Rui, O.M. (2001) Stock returns and volatility on China's stock markets, Journal of Financial Research, 24(4), 523-543.

27. Lo, A. and MacKinlay, A. C. (1988). Stock market prices do not follow random walks: Evidence from a simple specification test, Review of Financial Studies, 1(1), 41-66.

28. Poshakwale, S. (1996). Evidence on Weak Form Efficiency and Day of the Week Effect in the Indian Stock Market. Finance India, Vol X, No. 3. 605-616.

29. Regúlez, M. and Zarraga, A. (2002) Common features between stock returns and trading volume, Applied Financial Economics, 12(12), 885-893.

30. Rutterford, J. (1993). Introduction to Stock Exchange Investment, Second Edition, 281-308, The Macmillan Press Ltd., London.

31. Ryoo, H.J. and Smith, G. (2002) Korean stock prices under price limits: Variance ratio tests of random walks, Applied Financial Economics, 12(8), 545-553. 
32. Samuelson, P. (1965). Proof that Properly Anticipated Prices Fluctuate Randomly. Industrial Management Review. Spring 6, 41-49.

33. Smith, G., Jefferis, K., and Ryoo, H.J. (2002) African stock markets: multiple variance ratio tests of random walks, Applied Financial Economics, 12(4), 475-484.

34. Will, M. (2006) The Role of Performances in an Accounting Scandal: An Insider's Perspective on How Things Went Wrong', Proceedings of $5^{\text {th }}$ Global Conference on Business \& economics, Cambridge University, UK, Paper No. 152.

35. Worthington, A. C. and Higgs, H. (2003). Weak-form Market Efficiency in European Emerging and Developed Markets, Discussion paper no. 159, School of Economics and Finance, Queensland University of Technology, Brisbane, Australia http://nseindia.com/content/indices/ind faq8.htm, accessed on ${ }^{\text {st }}$ September 2006.

\section{NOTES}

